\title{
Protein kinase Akt2/PKB $\beta$ is involved in blastomere proliferation of preimplantation mouse embryos
}

\author{
Maria Teresa Fiorenza, ${ }^{1,2}$ | Giandomenico Russo ${ }^{3}$ | Maria Grazia Narducci $^{3} \mid$ \\ Antonella Bresin $^{3}$ | Franco Mangia ${ }^{1}$ | Arturo Bevilacqua ${ }^{4}$ (1)
}

${ }^{1}$ Department of Psychology, Division of Neuroscience and "Daniel Bovet" Neurobiology Research Center, Sapienza University of Rome, Rome, Italy

${ }^{2}$ IRCCS Fondazione Santa Lucia, Rome, Italy ${ }^{3}$ IDI, IRCCS, Rome, Italy

${ }^{4}$ Department of Dynamic and Clinical Psychology, Sapienza University of Rome, and Systems Biology Group Lab, Rome, Italy

\section{Correspondence}

Maria Teresa Fiorenza, Department of Psychology, Division of Neuroscience and "Daniel Bovet" Neurobiology Research Center, Sapienza University of Rome, Rome, Italy. Email: mariateresa.fiorenza@uniroma1.it

Arturo Bevilacqua, Department of Dynamic and Clinical Psychology, Sapienza University of Rome, and Systems Biology Group Lab, Rome, Italy.

Email: arturo.bevilacqua@uniroma1.it

Funding information

Ministero della Salute, Grant/Award Number: Ricerca Corrente; Sapienza Università di Roma, Grant/Award Number: C26A14RMK5; Sapienza grants, Grant/Award Number: C26A14RMK5; Ministero della Salute Ricerca Corrente

\begin{abstract}
Activation of Akt/Protein Kinase B (PKB) by phosphatidylinositol-3-kinase (PI3K) controls several cellular functions largely studied in mammalian cells, including preimplantation embryos. We previously showed that early mouse embryos inherit active Akt from oocytes and that the intracellular localization of this enzyme at the two-cell stage depends on the T-cell leukemia/lymphoma 1 oncogenic protein, Tcl1. We have now investigated whether Akt isoforms, namely Akt1, Akt2 and Akt3, exert a specific role in blastomere proliferation during preimplantation embryo development. We show that, in contrast to other Akt family members, Akt2 enters male and female pronuclei of mouse preimplantation embryos at the late one-cell stage and thereafter maintains a nuclear localization during later embryo cleavage stages. Depleting one-cell embryos of single Akt family members by microinjecting Akt isoform-specific antibodies into wild-type zygotes, we observed that: (a) Akt2 is necessary for normal embryo progression through cleavage stages; and (b) the specific nuclear targeting of Akt2 in two-cell embryos depends on Tcl1. Our results indicate that preimplantation mouse embryos have a peculiar regulation of blastomere proliferation based on the activity of the Akt/PKB family member Akt2, which is mediated by the oncogenic protein Tcl1. Both Akt2 and Tcl1 are essential for early blastomere proliferation and embryo development.
\end{abstract}

\section{KEYWORDS}

Akt/PKB isoforms, Akt2, mouse preimplantation embryos, Tcl1

\section{1 | INTRODUCTION}

Among the downstream mediators of the phosphatidylinositol-3-kinase (PI3K) signaling pathway via the recruitment of pyruvate dehydrogenase kinase 1 (PDK1), the serine/threonine Akt kinase (also named PKB) plays a crucial role in mammalian physiology, controlling basic cellular functions such as glucose metabolism, cell survival and proliferation, transcription and cell migration (Hajduch et al., 2001; Manning \& Cantley, 2007; Dummler \& Hemmings, 2007; Fayard et al., 2010). PI3K is also necessary for preimplantation development (Lu, Chandrakanthan, Cahana, Ishii, \& O'Neill, 2004; Halet et al., 2008), as indicated by the lethal embryonic phenotype elicited by the genetic deletion of the P110 beta catalytic subunit of PI3K in the mouse (Bi, Okabe, Bernard, \& Nussbaum, 2002). Several cytokines and/or growth factors stimulate PI3K activity, causing an increased production of phosphatidylinositol second messengers within the plasma membrane (Leevers et al., 1999). Among these messengers, phosphatidylinositol-3,4,5-trisphosphate (PIP3) forms a docking site for Akt, which, in turn, presents two phosphorylation sites, one at serine 473 (ser-473) in the C-terminal domain and one at threonine 308 (threo-308) in the activation loop. Akt binding to PIP3 and association with PDK1 induces phosphorylation of threo-308 (Alessi et al., 1997), an essential prerequisite for its catalytic activity (Pearce, Komander, \& Alessi, 2010), and apparently inhibits that of ser-473, making the phosphorylation of the latter residue inducible by other 
upstream signals; in contrast, the phosphorylation of threo-308 appears to escape other inducing signals (Downward, 1998) but can be reduced by protein phosphatases (Chan et al., 2015). In accordance with this model, the full activation of Akt in human cells requires phosphorylation of ser-473 by rictor-mTOR complex (Sarbassov, Guertin, Ali, \& Sabatini, 2005).

Mammalian cells express three distinct Akt kinase isoforms, Akt1, Akt2 and Akt3, also named $\mathrm{PKB} \alpha, \mathrm{PKB} \beta$ and $\mathrm{PKB} \gamma$, respectively, which share highly similar structures, including an $\mathrm{N}$-terminal regulatory pleckstrin homology $(\mathrm{PH})$ domain that binds PIP3, a central kinase domain with serine/threonine specificity, and a C-terminal hydrophobic domain (Brazil \& Hemmings, 2001). Despite their similar structures, the three Akt isoforms overlap only partly in terms of expression and functions. Akt1 is widely expressed, whereas Akt2 is prominently expressed in insulin-responsive cells, such as adipocytes, hepatocytes, skeletal muscle cells and adipose tissue, playing important roles in glucose metabolism and mitochondrial function (Chan et al., 2015), and Akt3 is the prominent brain isoform, suggesting isoform-specific function(s). Coherently, single Aktisoform knockout (KO) mice show distinct phenotypes. Akt1 KO mice have growth retardation and a smaller size compared to control littermates, along with increased neonatal death (Easton et al., 2005 Yang et al., 2005), whereas Akt2 KO mice develop a type 2 diabeteslike syndrome and Akt3 KO mice show decreased brain size (Cho, Thorvaldsen, Chu, Feng, \& Birnbaum, 2001; Easton et al., 2005; Tschopp et al., 2005).

Based on transcript and protein level determinations, mouse fertilized eggs and early embryos express Akt1, Akt2 and Akt3 encoding genes at similar levels (Cecconi et al., 2010; Hoshino \& Sato, 2008; Li, Chandrakanthan, Day, \& O'Neill, 2007) and immunostaining with a pan-Akt antibody shows the presence of Akt at all stages of early embryonic development (Riley et al., 2005). The presence of active Akt in the early mouse embryo was demonstrated in a previous study by our group (Fiorenza et al., 2008), showing that mouse zygotes inherit fully ser-473 and threo-308-phosphorylated Akt from the oocyte and that the phosphorylation levels and intracellular distribution of this enzyme during the first and second cell cycles are independent of PI3K and PDK1 activities (Fiorenza et al., 2008). Serine 473-/threonine 308-phosphorylated AKT acquires a prominent nuclear localization in mid-two-cell embryos relying on the function of T-cell leukemia/lymphoma 1 oncogenic protein, Tcl1 (Fiorenza et al., 2008). Tcl1 is a well-established coactivator of Akt (Laine, Künstle, Obata, Sha, \& Noguchi, 2000; Paduano et al., 2018; Pekarsky et al., 2000) and the causative oncogene of T-prolymphocytic leukemia (T-PLL), AKT (Virgilio et al., 1994). Tcl1 has pathogenic implications also in B-Chronic lymphocytic leukemia (Bichi et al., 2002; Bresin et al., 2016), in $\mathrm{CD}^{+} / \mathrm{CD} 56^{+}$ skin blastic tumors (Herling, Teitell, Shen, Medeiros, \& Jones, 2003) and is also expressed in epidermal stem cells during hair follicle regeneration (Bresin et al., 2018; Ragone et al., 2009) and in preimplantation mouse embryo blastomeres (Narducci et al., 2002).

In the present study, we have addressed the issue of whether different Akt isoforms exert idiosyncratic roles and interact with $\mathrm{Tcl} 1$ during preimplantation mouse embryo development. This system is of particular interest because preimplantation embryos express Akt1, Akt2, Akt3 and Tcl1 concomitantly, thus representing an excellent tool to investigate the functional interactions between these factors in a fully physiological fashion. To this end, we have determined the expression and intracellular localization of the three Akt isoforms in isolated mouse embryos that were cultured in vitro from the one-cell stage to the blastocyst stage. Thereafter, we have directly investigated the contribution of each isoform to blastomere proliferation by injecting isoform-specific Akt antibodies into one-cell embryos and then monitoring the development of these embryos to the blastocyst stage. We finally assessed whether the intracellular localization of specific Akt isoform(s) depends on Tcl1 by exploitingTcl1-deficient embryos, either obtained from $\mathrm{Tcl}^{-/-}$mice (Narducci et al., 2002) or experimentally produced by the injection of anti-Tcl1 antibodies at the one-cell stage.

\section{2 | MATERIALS AND METHODS}

\subsection{Embryo isolation, in vitro culture and microinjection}

Animals used in this study were B6D2F1/J hybrid mice (Charles River Italia, Calco, Italy), Akt1-, Akt2-, and Akt3-KO mice (kindly provided by Dr. Brian Hemmings, Friedrich Miescher Institute for Biomedical Research, Basel, Switzerland), and Tcl1- KO mice (Narducci et al., 2002), bred in our colony. Wild-type mouse eggs were routinely obtained from B6D2F1/J hybrid mice using hormonally primed 40-60-day-old females and mated with adult males, as already described (Colazingari, Fiorenza, Carlomagno, Najjar, \& Bevilacqua, 2014). The midnight after mating was taken as the fertilization time. Routinely, one-cell embryos were collected 10-12 hr after fertilization, and cultured in vitro up to 4 days, as described (Bevilacqua, Fiorenza, \& Mangia, 2000). Culture media used were M2 and KSOM. In vitro cultured embryos were monitored daily under a Wild stereomicroscope (Leica Microsystems, Wetzlar, Germany) and scored for the presence of pronuclei, cleavage progression and morphology. For microinjection, antibodies were prepared as previously described (Bevilacqua et al., 2000). Briefly, antibodies were microdialyzed against $10 \mathrm{mM}$ Tris- $\mathrm{HCl}, \mathrm{pH}$ 7.4, $0.1 \mathrm{mM}$ ethylenediaminetetraacetic acid (TE) using MF filters (Millipore, Rome, Italy) and then diluted to a final concentration of approximately $125-250 \mathrm{ng} / \mu \mathrm{L}$ in TE. Microinjections of anti-Tcl1, anti-Akt1, anti-Akt2, anti-Akt3 antibodies in one-cell embryos (approximately $5 \mathrm{pL}$ ) were performed $14-16 \mathrm{hr}$. after fertilization, as previously described (Narducci et al., 2002). Pre-immune rabbit IgG (Sigma) were used as control antibodies (not shown). Survival of injected onecell embryos was 40-50\%. Damaged embryos were immediately discarded and not considered for subsequent assays. Surviving embryos were further cultured, as described. $\mathrm{Tcl}^{-/-}$eggs were obtained by crossing hormonally primed 40 - to 60 -day-old $\mathrm{Tcl}^{-/-}$ females with $\mathrm{Tcl}^{-1-}$ males. Akt1 $1^{-/-}, \mathrm{Akt}^{-/-}$, and $\mathrm{Akt}^{-/-}$morulas were obtained by crossing hormonally primed 40-60-day-old $\mathrm{KO}$ 
females with $\mathrm{KO}$ males. The tubes were dissected and torn with a sharp needle approximately $60 \mathrm{hr}$ after fertilization. Released embryos were fixed in $2.4 \%$ paraformaldehyde in phosphate buffered saline (PBS) for 30 min at RT, washed three times in PBS, stained with Hoechst ( $10 \mathrm{mg} / \mathrm{ml}$ Hoechst 33343 in PBS) for 5 min and mounted on glass slides. The total number of stained nuclei of each embryo was counted under a Zeiss Axioplan fluorescence microscope equipped with a Cool Snap K4 Photometrics.

Experimental protocols and related procedures were approved by the Italian Ministry of Public Health. All experiments were conducted according to the Italian law DL 26/2014 on the protection of animals used for scientific purposes.

\section{2 | Antibodies}

Purified rabbit IgG directed to AKT isoforms (AKT1, cat \#06-558, AKT2, cat \#06-606, AKT3, cat \#06-607; Upstate Biotechnology, Lake Placid, NY) were used for microinjection of mouse embryos and immunofluorescence analyses. Purified mouse anti- $\beta$-catenin IgG (cat \#610153; BD, Milano, Italy) were used for immunofluorescence analyses. A rabbit affinity-purified anti-murine Tcl1 polyclonal IgG (Narducci et al., 2002) was used for microinjection into mouse embryos.

\section{3 | Wide-field and confocal microscopy}

Embryos at the appropriate developmental stages were fixed in $2.4 \%$ paraformaldehyde in M2 medium for $1 \mathrm{hr}$ at room temperature (RT). Fixed embryos were carefully washed and incubated for $3 \mathrm{hr}$ in PBS containing $0.1 \mathrm{M}$ glycine and $0.3 \mathrm{mg} / \mathrm{ml}$ bovine serum albumin (BSA) and then permeabilized in PBS containing 0.1\% Triton X-100 for $15 \mathrm{~min}$ at RT. Embryos were washed in PBS containing $1 \mathrm{mg} / \mathrm{ml}$ bovine serum albumin (BSA) (PBS-BSA) and then processed for immunostaining with antibodies directed to Akt1/2/3 isoforms (1:200 dilution in PBS containing 1\% BSA) or $\beta$-Catenin (1:100 in PBS containing 1\% BSA) acc. to published procedures (Fiorenza et al., 2008; Narducci et al., 2002) or manufacturer's recommendations. Secondary antibodies (Santa Cruz Biotechnology, Heidelberg, Germany) were FITC-labeled. Nuclei were stained with $1 \mathrm{mg} / \mathrm{ml}$ propidium iodide (PI). Specimens were mounted on slides and observed under a Zeiss wide-field fluorescence microscope and/or laser scanning confocal microscopy (Leica, TCS, NT), as needed (Canterini et al., 2012).

Quantitative fluorescence analyses of Akt isoforms were performed by wide-field microscopy using a Zeiss Axiophot microscope equipped with a Prior Proscan II z-axis controller and a cooled CCD camera CoolSnapK4 (Photometrics). The total fluorescence of each embryo was calculated as sum of the optical densities of images acquired using the Metamorph Imaging System software (Universal Imaging, Philadelphia, PA), as previously described (Fiorenza et al., 2008).

\section{4 | Reagents}

Chemicals and reagents were from Sigma (Sigma-Aldrich, Milan, Italy) except when otherwise specified in the text. Pregnant mare serum gonadotropin and human chorionic gonadotropin (Corulon ${ }^{\circledR}$ ) used for hormonal priming were from NHPP (Torrence, CA) and Intervet Italia (Aprilia, Italy), respectively.

\section{5 | Data analysis}

Effects of antibody injections on embryo development to various preimplantation stages were analyzed by Student's $t$ test. Distributions of quantitative immunofluorescence measurements of embryos stained with Akt1, Akt2, and Akt3 antibodies were evaluated by Fisher's F-test. Differences in blastomere numbers between morulastage Akt1 KO, Akt2 KO, Akt3 KO embryos and wild-type embryos were evaluated by Student's $t$ test.

Statistical analyses were performed using R: A language and environment for statistical computing ( $R$ development core team, $R$ foundation for statistical computing, ISBN 3-900051-07-0, 2008, Vienna, Austria. http://www.R-project.org).

\section{3 | RESULTS}

\subsection{Preimplantation mouse embryos display the three Akt isoforms}

The presence and intracellular localization of Akt isoforms $A k t 1 / P K B \alpha$, $A k t 2 / P K B \beta$ and $A k t 3 / P K B \gamma$ in early embryos were investigated by immunofluorescence using Akt isoform-specific antibodies (Figure 1a,b) followed by quantitative densitometric analysis (Figure 1c). Akt1 was evenly distributed in the cytosol and pronuclei/nuclei of one-cell and early two-cell embryos but significantly decreased thereafter, becoming below detection levels in four-cell and eight-cell embryos (not shown). In contrast, the presence of Akt2 was consistently detected in fertilized eggs and developing embryos through all cleavage stages. Although restricted to the cytoplasm in early one-cell embryos, this isoform displayed a nuclear localization in late one-cell embryos (not shown) and during subsequent cleavage stages. The amount of Akt2 exceeded that of Akt1 several-fold in one- and two-cell embryos (4.08- and 3.24-fold respectively), of 3.04-fold in four-cell embryos and of 3.94-fold in eight-/ 16-cell embryos. Akt3 displayed a cytoplasmic localization in one-/twocell embryos and, similarly to AKT1, appeared poorly detectable during embryo cleavage following the two-cell stage, except for a peculiar localization at the blastomere boundary. The amount of Akt3 was slightly more abundant than that of Akt1 at all stages (1.63-fold in onecell embryos, 1.32-fold in two-cell embryos, 1.23-fold in four-cell embryos and 1.24-fold in eight-/16-cell embryos). When compared by Fisher F-test, the pattern of Akt2 abundance was significantly different from those relative to Akt1 and Akt3 $(p<.05)$.

\subsection{The deficiency in the Akt isoform Akt2, but not Akt1/Akt3, impairs embryo blastomere proliferation}

To determine whether Akt1, Akt2, and Akt3 play idiosyncratic roles during preimplantation embryo development, we analyzed the in 
(a)
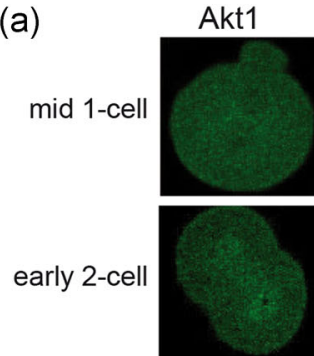

mid 2-ce

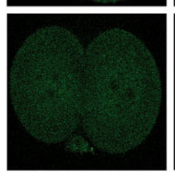

(b)

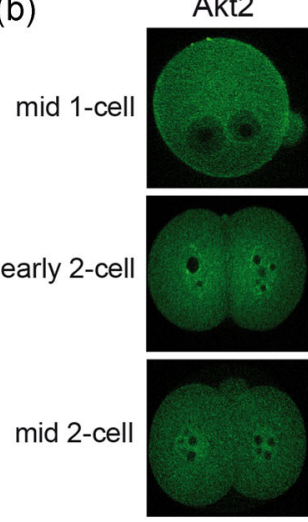

Akt2
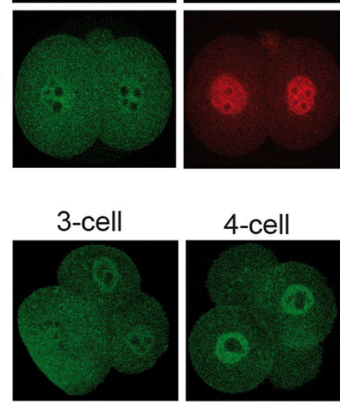
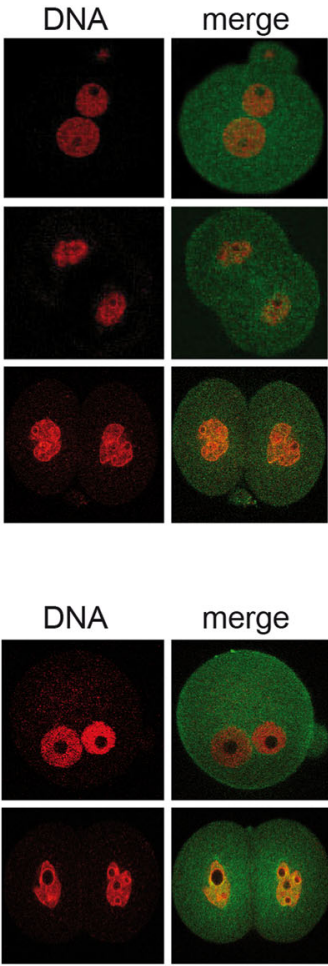

merge

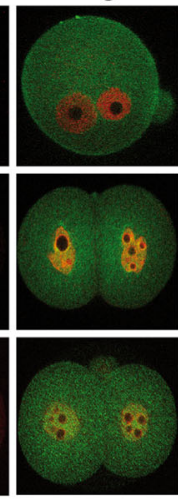

4-cell

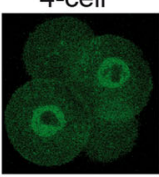

8-cell

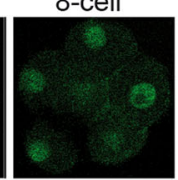

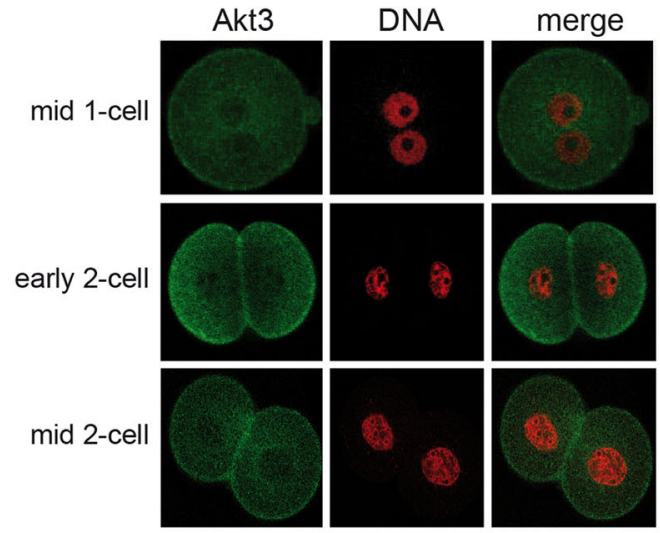

(C)

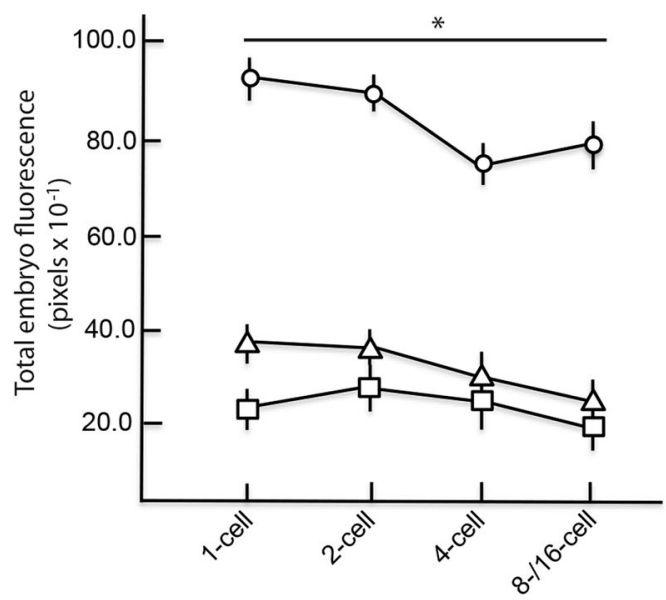

Developmental stages

FIGURE 1 (a) Expression of Akt isoforms Akt1 and Akt3 in fertilized eggs and two-cell embryos. (b) Expression of Akt2 in fertilized eggs and cleavage-stage embryos. One-cell embryos (mid one-cell, stage PN3, acc. to Adenot, Mercier, Renard, \& Thompson, 1997), early/mid-two-cell embryos and three-/four-/eight-cell embryos were immunostained with isoform-specific antibodies and then analyzed by confocal microscopy. Nuclei were stained with propidium iodide. Four-/eight-cell embryos immunostained with Akt1 or Akt3 antibodies were below detection levels (not shown). Representative embryos are shown in the panels. (c) Total embryo amount of Akt1 ( $\square$ ), Akt2 (O), Akt3 ( $\Delta$ ) at the indicated stages was determined by immunostaining with Akt isoform-specific antibodies, followed by quantitative immunofluorescence analysis, as described under Section 2. All data are expressed as mean $\pm S E M ;{ }^{*} p<.05$, calculated by Fisher F-test [Color figure can be viewed at wileyonlinelibrary.com]

vitro development of embryos that were specifically depleted of a single Akt isoform by injection of specific antibodies into fertilized eggs. The depletion of Akt1 or Akt3 by antibody neutralization had no apparent effect on preimplantation development (Figure 2a,b). In fact, both Akt1- and Akt3-depleted embryos successfully developed to the blastocyst stage in a fashion similar to that of sham-injected embryos (Akt1 antibody-injected blastocysts vs. sham-injected blastocysts, $p=.149$; Akt3 antibody-injected blastocysts vs. shaminjected blastocysts, $p=.793$ ).

In contrast, the injection of anti-Akt2 antibodies negatively affected embryo cleavage as early as during the second cell cycle, significantly reducing the fraction of embryos developing to the fourcell, the eight-/16-cell and blastocyst stages (Figure 3, left; Akt2 antibody-injected embryos vs. sham-injected embryos: four-cell stage, $\quad p<.01$; eight-/16-cell stage, $p<.05$; blastocyst stage, $p<.001)$. Interestingly, Akt2 depletion did not affect the occurrence/timing of embryo compaction, as evaluated by $\beta$-catenin immunostaining of blastomere boundaries (Figure 3, right; Pauken \& Capco, 1999). Although normally compacted, however, confocal microscopy analysis of Akt2-depleted morulas and control embryos at the same stage revealed that antibody-injected embryos were composed of smaller numbers of larger blastomeres, a feature that we already observed in $\mathrm{Tcl}^{-1-}$ embryos (Narducci et al., 2002; Figure 3). Effects of Akt1-, Akt2- and Akt3-antibody injections on blastomere numbers in morula-stage embryos were further evaluated by a comparison to features typical of $A k t 1^{-/-}, A k t 2^{-/-}$, and $A k t 3^{-/-}$embryos at the same stage. Akt2-KO, but not Akt1- nor Akt3$\mathrm{KO}$ morulas, displayed a reduced number of blastomeres when 
(a)

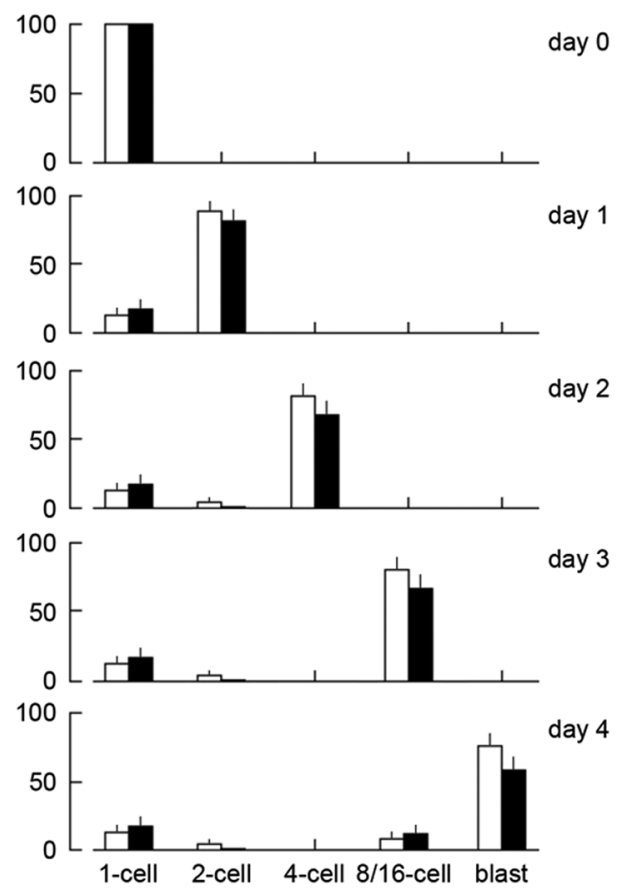

(b)

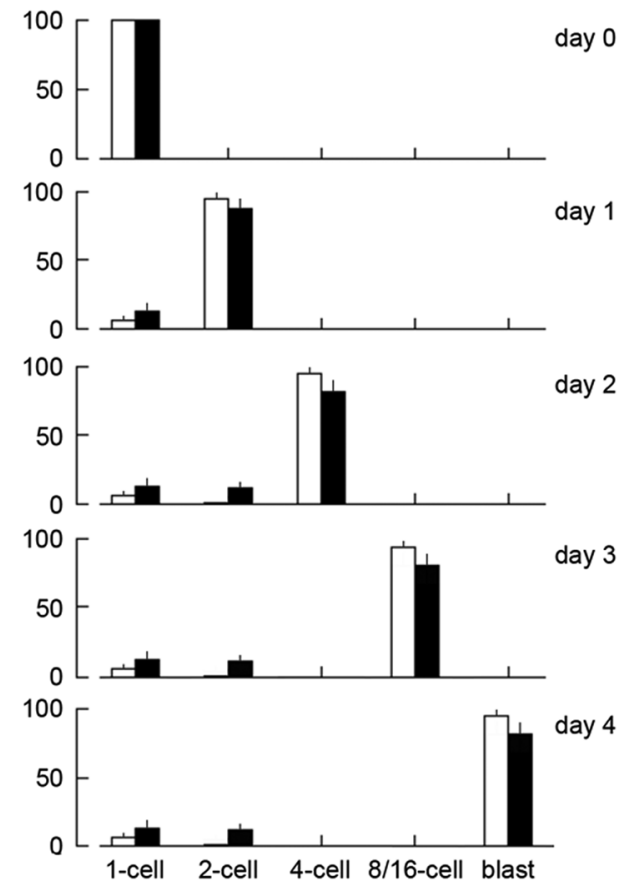

FIGURE 2 Dispensability of Akt1 and Akt3 isoforms for preimplantation embryo development. Embryos received an injection of either plain buffer (mock, empty bars) or anti-Akt1 (a) and anti-Akt3 (B) antibodies (full bars) at the late one-cell stage. Surviving embryos were then allowed to develop in vitro and daily scored for 4 days for developmental stage and morphology. Day 0 indicates the day of injection. Bars (mean \pm SEM of four independent experiments having 12-20 injected embryos in each experimental group) indicate the distribution of in vitro cultured embryos among the developmental stages indicated in the abscissae

compared with wt embryos (Table 1), fully confirming results obtained with antibody microinjections.

\section{3 | Tcl1 is required for Akt2 nuclear localization}

The similarity of the large-blastomere phenotype of Akt2- and Tcl1defective embryos prompted us to investigate the functional relationship between Akt2 and Tcl1 during preimplantation development, addressing the question of whether Akt2 intracellular localization at one- and two-cell stages depended on Tcl1. To this end, we performed Akt1, Akt2 or Akt3 immunofluorescence analyses of two-cell embryos deficient in Tcl1 due to either an experimental Tcl1 depletion by injection of anti-Tcl1 antibodies at the one-cell stage, or to a $\mathrm{TCl}^{-/-}$genotype (Narducci et al., 2002). The injection of anti-Tcl1 antibodies had no apparent effect on either Akt1 or Akt3 cytoplasmic/nuclear localization (Figure 4). In contrast, both wildtype embryos receiving anti-Tcl1 antibodies and $\mathrm{TCl}^{-1-}$ embryos displayed the absence of nuclear Akt2, accompanied by a significant abnormal Akt2 increase at the level of embryo cortical regions, suggesting a block of intracellular Akt2 mobilization.

\section{4 | DISCUSSION}

Genetic and pharmacological approaches have demonstrated the relevance of Akt activation for early embryo cleavage. For instance,
mRNA encoding a constitutively active myristoylated Akt injected into mouse zygotes enhanced their rate of cell division, whereas that of kinase-deficient Akt mRNA delayed the onset of the first cell cycle (Feng et al., 2007). However, the three Akt isoforms appear to play nonredundant functions (Dummler \& Hemmings, 2007), raising the question of whether the signaling of a specific Akt isoform is required during early stages of mouse embryonic development.

Present immunofluorescence analysis of Akt isoforms makes any involvement of Akt1 and Akt3 in the control of cleaving preimplantation embryos unlikely, but pinpoints to a major regulatory role for Akt2. During the transition from the one-cell stage to the two-cell stage, Akt2 is typically cytoplasmic in newly fertilized eggs, but is thereafter mobilized to both pronuclei in late one-cell embryos, maintaining a nuclear localization during further development through cleavage. It was previously shown that the pronuclear presence of p-ser-473 Akt in one-cell embryos is required for the occurrence of the first mitosis (Baran, Fabian, \& Rehak, 2013). On the other hand, the nuclear localization of p-ser473 Akt in two-cell embryos was recently associated with the major wave of transcriptional activation of the zygotic genome and the progression through embryo cleavages (Chen et al., 2016). The Akt protein described by these groups is likely to be represented by either the Akt1 or the Akt2 isoform that fertilized eggs inherit from oogenesis (Cecconi et al., 2010; Cecconi et al., 2012), which is fully active (Fiorenza et al., 2008) and likely relevant at fertilization. For instance, a recent study reported that Akt1 regulates the 
(a)

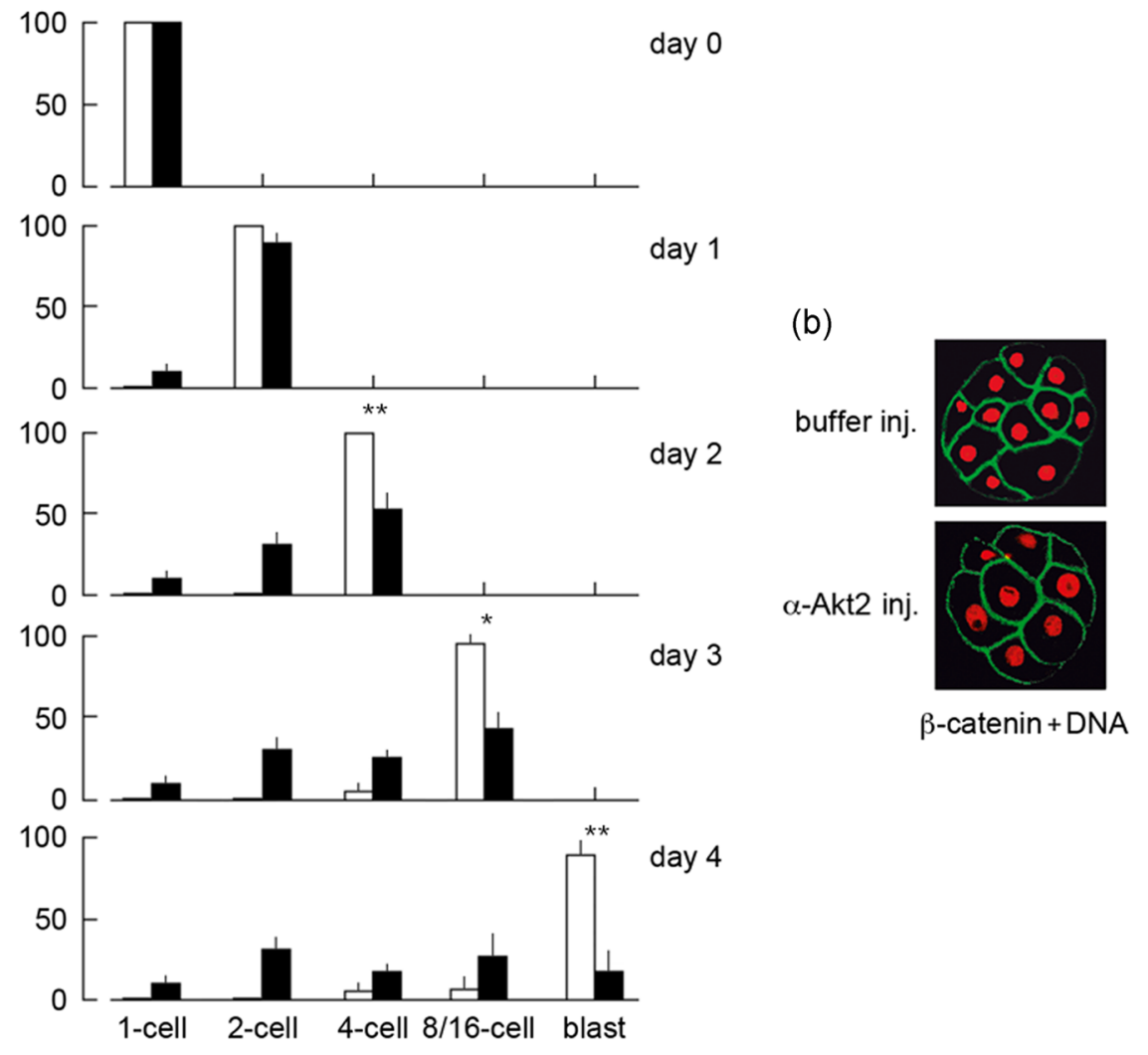

FIGURE 3 Dependency of preimplantation embryo development on Akt2 isoform. (a) Embryos received an injection of either plain buffer (mock, empty bars) or anti-Akt2 antibodies (full bars) at the late one-cell stage. Surviving embryos were then in vitro cultured and scored for progression through cleavage stages, as described in the legend of Figure 2. Bars (mean \pm SEM of four independent experiments having 12-20 injected embryos in each experimental group) indicate the distribution of in vitro cultured embryos among developmental stages, indicated in the abscissae. Asterisks indicate statistical significance versus mock, ${ }^{*} p<.05 ;{ }^{* *} p<.01$, calculated by Student's $t$ test. (b) Immunofluorescence detection of $\beta$-catenin, depicting cell boundaries, using FITC-labeled antibodies, in representative compacted morula-stage embryos. Blastomere nuclei were stained with propidium iodide. Embryos that had received an injection of plain buffer or anti-Akt2 antibodies at the one-cell stage were cultured in vitro for 3 days and finally processed for immunostaining and confocal microscopy analysis. Representative embryos are shown in the panels [Color figure can be viewed at wileyonlinelibrary.com]

remodeling of actin filaments in one-cell mouse embryos $(\mathrm{Wu}, \mathrm{Yu}$, Wang, \& Yu, 2016). However, at later stages of development, the presence of Akt1 is barely detectable, in agreement with the apparently normal development of Akt1 antibody-injected embryos of present experiments. Taken together, these observations suggest that the Akt1 isoform has a limited temporal window of activity in fertilized mouse eggs. As for Akt3, present results make unlikely a

TABLE 1 Blastomeres of $A k t 1^{-/-}, A k t 2^{-/-}$, and $A k t 3^{-/-}$morulastage embryos developed in vivo

\begin{tabular}{llll}
$\begin{array}{l}\text { Geno- } \\
\text { type }\end{array}$ & $N^{a}$ & $\begin{array}{l}\text { Blastomere } \\
\text { number }\end{array}$ & $p^{c}$ \\
\hline wt & 40 & $10.54 \pm 1.55$ & - \\
Akt1 $^{-/-}$ & 31 & $10.16 \pm 1.95$ & .435 \\
Akt2 $^{-/-}$ & 27 & $8.33 \pm 1.36$ & $<.001$ \\
Akt3 $^{-/-}$ & 38 & $10.39 \pm 1.50$ & .717 \\
\hline
\end{tabular}

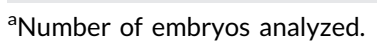

${ }^{b}$ Mean $\pm S D$.

'Difference with wt calculated by Student's $t$ test. specific role of this isoform in the progression of preimplantation mouse embryos through cleavage stages.

On the other hand, present immunofluorescence analysis, antibody microinjections and observed blastomere numbers of Akt2-KO embryos at the morula stage pinpointed Akt2 as having a relevant role in cleaving mouse blastomeres. In agreement with the Akt activation model (Sarbassov et al., 2005), trophic mediators that include autocrine trophic ligands, such as Paf (Lu et al., 2004), transforming growth factor- $\alpha$ (Kawamura, Fukuda, Shimizu, Kodama, \& Tanaka, 2005), insulin and insulin-like growth factor-1 (IGF-1; Navarrete Santos, Ramin, Tonack, \& Fischer, 2008), all known to support cell growth and proliferation in preimplantation embryos, induce ser-473 phosphorylation of this enzyme. Among the most likely transducers of Akt2 activation are the mediators of the PI3K pathway, including insulin and IGF-1. In agreement with this idea, we previously observed that PI3K activity is required for mouse preimplantation embryo development from the four/eight-cell stage (Fiorenza et al., 2008; Luconi et al., 2005), and that ser-473 phosphorylation but not threo-308 phosphorylation of Akt is 

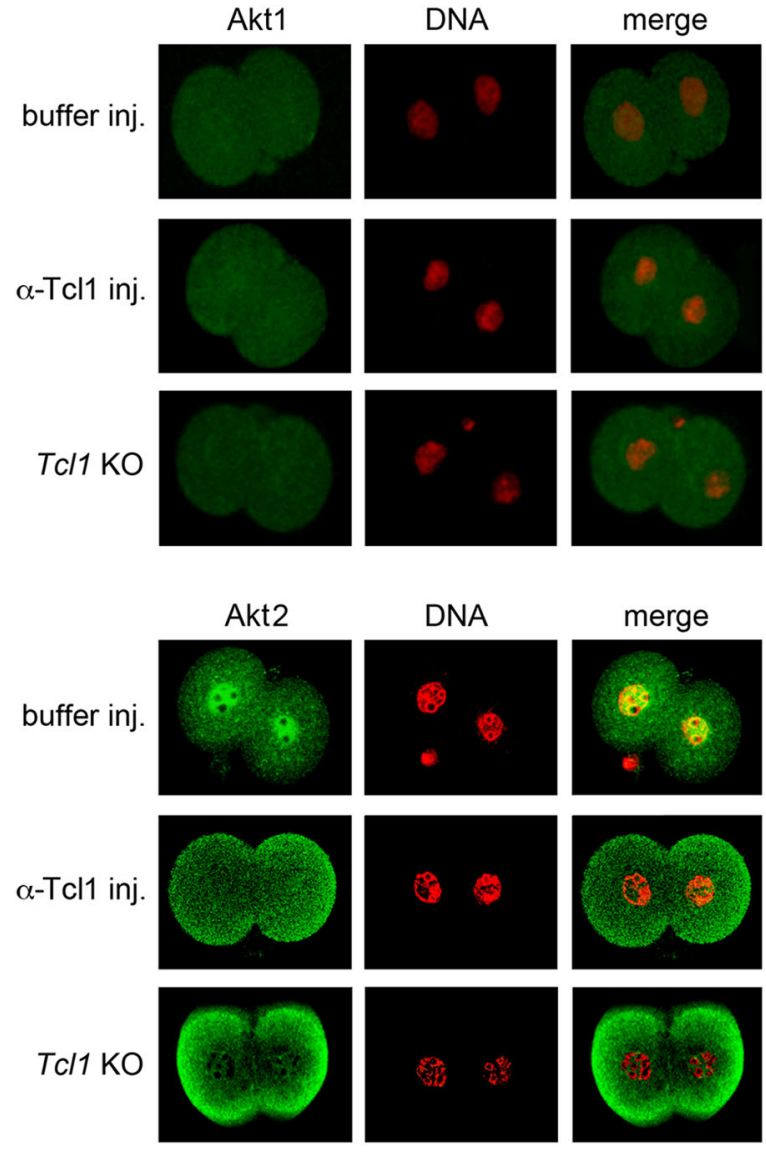

Akt3

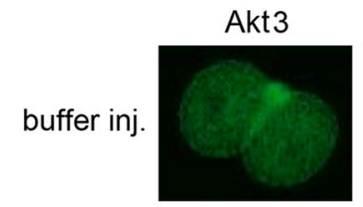

DNA

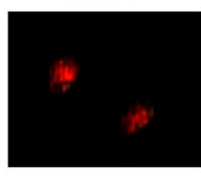

merge
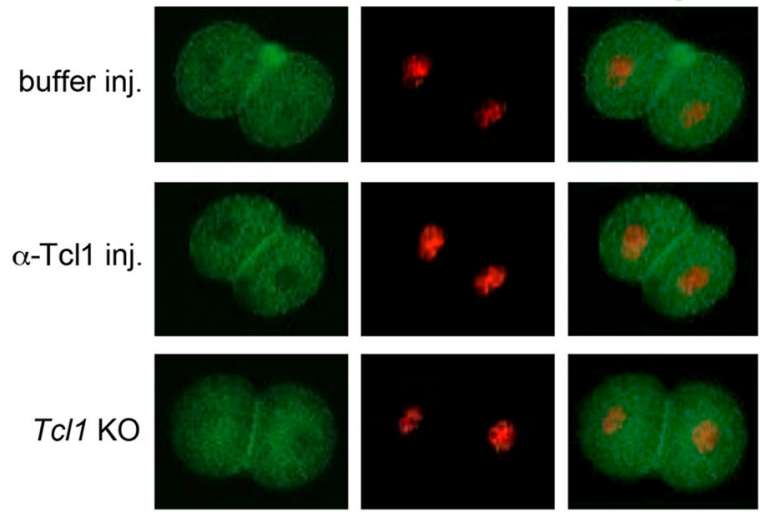

FIGURE 4 Dependency of Akt2 mobilization to nucleus on Tcl1 in two-cell embryos. Tcl1-deficient one-cell embryos, either experimentally produced by injection of $\mathrm{Tcl} 1$ antibodies or obtained from $\mathrm{Tcl}^{-1-}$ mice, were cultured in vitro until the two-cell stage, fixed and immunostained with Akt1 (Akt1), Akt2 (Akt2), or Akt3 (Akt3) antibodies, and finally analyzed by confocal microscopy. Nuclei were stained with propidium iodide. From left to right: fluorescein isothiocyanate-labelled antibody, propidium iodide, merge. Note the lack of nuclear Akt2 in embryos that had received an injection of anti-Tcl1 antibodies and in $\mathrm{TCl}^{-/-}$embryos. Representative embryos are shown in the panels [Color figure can be viewed at wileyonlinelibrary.com]

increased in early mouse blastocysts by supplementing culture media with myo-inositol (Kuşcu, Bizzarri, \& Bevilacqua, 2016), a precursor of phosphoinositides (Bevilacqua \& Bizzarri, 2016). It thus appears that new phosphorylation of Akt2 may occur after the first two/three embryo cleavages, depending on a transduction pathway(s) potentiated by mediators of the PI3K activity. As Akt2 is primarily expressed in insulin-responsive cells/tissues (Dummler \& Hemmings, 2007), we favor the possibility that the specific requirement of the Akt2 isoform for blastomere proliferation is related to the Akt2mediated regulation of cellular access to extracellular nutrients in response to insulin and IGF-1 and the switch to a glucose-dependent metabolism (Hardy et al., 1989) from the pyruvate/lactate-dependent one of oogenesis and early embryo development (Gardner, Lane, Stevens, \& Schoolcraft, 2001).

In regard to Tcl1-Akt interaction, present findings indicate that Akt2, but not other Akt isoforms, is the major downstream effector of Tcl1 in preimplantation blastomeres. In fact: (a) Akt2-deficient embryos displayed developmental defects similar to those of embryos lacking Tcl1, whereas the Akt1/Akt3 deficiency had no apparent effect; and (b) the nuclear Akt2 localization at the two-cell stage embryo was fully abolished by Tcl1 deficiency, whereas intracellular Akt1/Akt3 localizations were not. Tcl1 is known to positively regulate proliferation, differentiation, and apoptosis by Akt coactivation in response to growth factors including IGF-1, as recently shown in cell lines from both Tcl1-KO and transgenic Tcl1-overexpressing mice (Bresin et al., 2018). Tcl1 binds different Akt isoforms in the various systems studied, suggesting the existence of a large variety of heterooligomers arising from the combination of Akt isoforms, Tcl1 family members, and cell/tissue-specific factors (French et al., 2002; Laine et al., 2000; Laine, Künstle, Obata, \& Noguchi, 2001; Pekarsky et al., 2000). However, despite its recognized role in the enhancement of multiple signaling pathways, including PI3K, the enzymatic activity of Tcl1 is still not well-defined (Paduano et al., 2018).

Mobilization of Akt2 from the cytoplasm to the nucleus at the two-cell stage may be necessary for the occurrence of the major wave of transcriptional activation of the zygotic genome and the progression through embryo cleavages, as recently suggested by Chen et al. (2016). The presence and activity of Akt2 is necessary for embryo blastomere proliferation but not other morphogenetic processes such as compaction during later cleavage stages. This appears to be under ser-473 control, as addition of myo-inositol to culture media increases both ser-473 but not threo-308 phosphorylation (Kuşcu et al., 2016) and the average number of blastomeres present in embryos at the blastocyst stage (Colazingari et al., 2014).

Akt2 thus appears as a main regulator of preimplantation embryo progression by closely controlling the proliferative activity of early blastomeres. Additional experiments are necessary to further analyze its pro-mitotic role in this system, in light of its described interaction and inhibition of the proapoptotic transcriptional activator FoxO (Zhang, Tang, Hadden, \& Rishi, 2011), and the role of pro- and antiapoptotic factors of the Bcl-2 family (Azadbakht, Valojerdi, \& Mowla, 2007).

\section{ACKNOWLEDGMENTS}

We thank Dr. Simona Torcia for help with mouse genotyping and embryo collection and Dr. Sonia Canterini for image processing. This 
study was supported by Sapienza grants (\#C26A14RMK5) to M. T. F. and Ministero della Salute Ricerca Corrente to G. R.

\section{CONFLICT OF INTERESTS}

The authors declare that there are no conflict of interests.

\section{AUTHOR CONTRIBUTIONS}

M. T. F. and A. B. conceived the study, performed immunofluorescence and microinjection experiments, analyzed the data and wrote the manuscript. M. G. N. and A. B. contributed to immunofluorescence experiments, imaging acquisition, analysis and interpretation. G. R. and F. M. contributed with advice, discussion and data interpretation.

\section{DATA AVAILABILITY STATEMENT}

Data supporting present findings are available from the corresponding author upon reasonable request.

\section{ORCID}

Maria Teresa Fiorenza (D) http://orcid.org/0000-0002-5079-4019 Arturo Bevilacqua (D) http://orcid.org/0000-0002-8889-2634

\section{REFERENCES}

Adenot, P. G., Mercier, Y., Renard, J. P., \& Thompson, E. M. (1997). Differential $\mathrm{H} 4$ acetylation of paternal and maternal chromatin precedes DNA replication and differential transcriptional activity in pronuclei of 1-cell mouse embryos. Development, 124, 4615-4625.

Alessi, D. R., James, S. R., Downes, C. P., Holmes, A. B., Gaffney, P. R. J., Reese, C. B., \& Cohen, P. (1997). Characterization of a 3-phosphoinositide-dependent protein kinase which phosphorylates and activates protein kinase B $\alpha$. Current Biology, 7(4), 261-269.

Azadbakht, M., Valojerdi, M. R., \& Mowla, S. J. (2007). Development of mouse embryos co-cultured with polarized or non-polarized uterine epithelial cells using sequential culture media. Animal Reproduction Science, 100, 141-157.

Baran, V., Fabian, D., \& Rehak, P. (2013). Akt/PKB plays role of apoptosis relay on entry into first mitosis of mouse embryo. Zygote, 21, 406-416.

Bevilacqua, A., \& Bizzarri, M. (2016). Physiological role and clinical utility of inositols in polycystic ovary syndrome. Best Practice \& Research Clinical Obstetrics \& Gynaecology, 37, 129-139.

Bevilacqua, A., Fiorenza, M. T., \& Mangia, F. (2000). A developmentally regulated GAGA box-binding factor and $\mathrm{Sp} 1$ are required for transcription of the hsp70.1 gene at the onset of mouse zygotic genome activation. Development, 127, 1541-1551.

Bi, L., Okabe, I., Bernard, D. J., Nussbaum, R. L., Bi, L., Okabe, I., ... Nussbaum, R. L. (2002). Early embryonic lethality in mice deficient in the $\mathrm{p} 110 \beta$ catalytic subunit of PI 3-kinase. Mammalian Genome, 13, 169-172.

Bichi, R., Shinton, S. A., Martin, E. S., Koval, A., Calin, G. A., Cesari, R., ... Croce, C. M. (2002). Human chronic lymphocytic leukemia modeled in mouse by targeted TCL1 expression. Proceedings of the National Academy of Sciences, 99(99), 6955-6960.

Brazil, D. P., \& Hemmings, B. A. (2001). Ten years of protein kinase B signalling: A hard Akt to follow. Trends in Biochemical Sciences, 26, 657-664.

Bresin, A., D'Abundo, L., Narducci, M. G., Fiorenza, M. T., Croce, C. M., Negrini, M., \& Russo, G. (2016). TCL1 transgenic mouse model as a tool for the study of therapeutic targets and microenvironment in human B-cell chronic lymphocytic leukemia. Cell Death \& Disease, 7, e2071.

Bresin, A., Ragone, G., Cristofoletti, C., Arcelli, D., Bassi, C., Caprini, E., ... Narducci, M. G. (2018). T Cell Leukemia/lymphoma $1 \mathrm{~A}$ is essential for mouse epidermal keratinocytes proliferation promoted by insulin-like growth factor 1. PLOS One, 13(10):e0204775.

Canterini, S., Bosco, A., Carletti, V., Fuso, A., Curci, A., Mangia, F., \& Fiorenza, M. T. (2012). Subcellular TSC22D4 localization in cerebellum granule neurons of the mouse depends on development and differentiation. The Cerebellum, 11, 28-40.

Cecconi, S., Mauro, A., Cellini, V., \& Patacchiola, F. (2012). The role of Akt signalling in the mammalian ovary. The International Journal of Developmental Biology, 56, 809-817.

Cecconi, S., Rossi, G., Santilli, A., Stefano, L. D., Hoshino, Y., Sato, E., ... Macchiarelli, G. (2010). Akt expression in mouse oocytes matured in vivo and in vitro. Reproductive BioMedicine Online, 20, 35-41.

Chan, T. O., Zhang, J., Tiegs, B. C., Blumhof, B., Yan, L., Keny, N., ... Penn, R. B. (2015). Akt kinase C-terminal modifications control activation loop dephosphorylation and enhance insulin response. Biochemical Journal, 471(1), 37-51.

Chen, J., Lian, X., Du, J., Xu, S., Wei, J., Pang, L., ... Wang, S. (2016). Inhibition of phosphorylated Ser473-Akt from translocating into the nucleus contributes to 2-cell arrest and defective zygotic genome activation in mouse preimplantation embryogenesis. Development, Growth \& Differentiation, 58, 280-292.

Cho, H., Thorvaldsen, J. L., Chu, Q., Feng, F., \& Birnbaum, M. J. (2001). Akt $1 / P K B \alpha$ is required for normal growth but dispensable for maintenance of glucose homeostasis in mice. Journal of Biological Chemistry, 276, 38349-38352.

Colazingari, S., Fiorenza, M. T., Carlomagno, G., Najjar, R., \& Bevilacqua, A. (2014). Improvement of mouse embryo quality by myo-inositol supplementation of IVF media. Journal of Assisted Reproduction and Genetics, 31, 463-469.

Downward, J. (1998). Mechanisms and consequences of activation of protein kinase B/Akt. Current Opinion in Cell Biology, 10, 262-267.

Dummler, B., \& Hemmings, B. A. (2007). Physiological roles of PKB/Akt isoforms in development and disease. Biochemical Society Transactions, 35, 231-235.

Easton, R. M., Cho, H., Roovers, K., Shineman, D. W., Mizrahi, M., Forman, M. S., ... Birnbaum, M. J. (2005). Role for Akt3/protein kinase B in attainment of normal brain size. Molecular and Cellular Biology, 25, 1869-1878.

Fayard, E., Xue, G., Parcellier, A., Bozulic, L., \& Hemmings, B. A. (2010). Protein kinase $B(P K B / A k t)$, a key mediator of the PI3K signaling pathway. Current Topics in Microbiology and Immunology, 346, 31-56.

Feng, C., Yu, A., Liu, Y., Zhang, J., Zong, Z., Su, W., ... Yu, B. (2007). Involvement of protein kinase B/AKT in early development of mouse fertilized eggs. Biology of Reproduction, 77, 560-568.

Fiorenza, M. T., Torcia, S., Canterini, S., Bevilacqua, A., Narducci, M. G., Ragone, G., ... Mangia, F. (2008). TCL1 promotes blastomere proliferation through nuclear transfer, but not direct phosphorylation, of AKT/PKB in early mouse embryos. Cell Death \& Differentiation, 15, 420-422.

French, S. W., Shen, R. R., Koh, P. J., Malone, C. S., Mallick, P., \& Teitell, M. A. (2002). A modeled hydrophobic domain on the TCL1 oncoprotein mediates association with AKT at the cytoplasmic membrane. Biochemistry, 41, 6376-6382. 
Gardner, D. K., Lane, M., Stevens, J., \& Schoolcraft, W. B. (2001). Noninvasive assessment of humanembryo nutrient consumption as a measure of developmental potential. Fertility and Sterility, 76, 1175-1180.

Hajduch, E., Litherland, G. J., \& Hundal, H. S. (2001). Protein kinase B (PKB/ Akt) - A key regulator of glucose transport? FEBS Letters, 492, 199-203.

Halet, G., Viard, P., \& Carroll, J. (2008). Constitutive PtdIns (3,4,5)P3 synthesis promotes the development and survival of early mammalian embryos. Development, 135, 425-429.

Hardy, K., Hooper, M. A. K., Handyside, A. H., Rutherford, A. J., Winston, R. M. L., \& Leese, H. J. (1989). Non-invasive measurement of glucose and pyruvate uptake by individual human oocytes and preimplantation embryos. Human Reproduction, 4, 188-191.

Herling, M., Teitell, M. A., Shen, R. R., Medeiros, L. J., \& Jones, D. (2003). TCL1 expression in plasmacytoid dendritic cells (DC2s) and the related $\mathrm{CD}^{+} \mathrm{CD}^{+} 6^{+}$blastic tumors of skin. Blood, 101, 5007-5009.

Hoshino, Y., \& Sato, E. (2008). Protein kinase B (PKB/Akt) is required for the completion of meiosis in mouse oocytes. Developmental Biology, 314, 215-223.

Kawamura, K., Fukuda, J., Shimizu, Y., Kodama, H., \& Tanaka, T. (2005). Survivin Contributes to the anti-apoptotic activities of transforming growth factor alpha in mouse blastocysts through phosphatidylinositol 3'-kinase pathway. Biology Reproduction, 73, 1094-1101.

Kuşcu, N., Bizzarri, M., \& Bevilacqua, A. (2016). Myo-inositol safety in pregnancy: From preimplantation development to newborn animals. International Journal of Endocrinology, 2016, 1-10.

Laine, J., Künstle, G., Obata, T., \& Noguchi, M. (2001). Differential regulation of Akt kinase isoforms by the members of the TCL1 oncogene family. Journal of Biological Chemistry, 277, 3743-3751.

Laine, J., Künstle, G., Obata, T., Sha, M., \& Noguchi, M. (2000). The protooncogene TCL1 is an Akt kinase coactivator. Molecular Cell, 6, 395-407.

Leevers, S. J., Vanhaesebroeck, B., \& Waterfield, M. D. (1999). Signalling through phosphoinositide 3-kinases: the lipids take centre stage. Curr Opin Cell Biol, 11(2), 219-225.

Li, Y., Chandrakanthan, V., Day, M. L., \& O’Neill, C. (2007). Direct evidence for the action of phosphatidylinositol $(3,4,5)$-trisphosphate-mediated signal transduction in the 2-cell mouse embryo. Biology of Reproduction, 77, 813-821.

Lu, D. P., Chandrakanthan, V., Cahana, A., Ishii, S., \& O’Neill, C. (2004). Trophic signals acting via phosphati dylinositol3 kinase are required for normal preimplantation mouse embryo development. Journal of Cell Science, 117, 1567-1576.

Luconi, M., Torcia, S., Grillo, D., Fiorenza, M. T., Forti, G., Mangia, F., \& Baldi, E. (2005). Enhancement of mouse sperm motility by the PI3- kinase inhibitor LY294002 does not result in toxic effects on preimplantation embryo development. Human Reproduction, 20(12), 3500-3504.

Manning, B. D., \& Cantley, L. C. (2007). AKT/PKB signaling: Navigating downstream. Cell, 129, 1261-1274.

Narducci, M. G., Fiorenza, M. T., Kang, S. -M., Bevilacqua, A., Di Giacomo, M., Remotti, D., ... Russo, G. (2002). TCL1 participates in early embryonic development and is overexpressed in human seminomas. Proceedings of the National Academy of Sciences, 99, 11712-11717.

Navarrete Santos, A., Ramin, N., Tonack, S., \& Fischer, B. (2008). Cell lineagespecific signaling of insulin and insulin-like growth factor I in rabbit blastocysts. Endocrinology, 149, 515-524.
Paduano, F., Gaudio, E., Mensah, A. A., Pinton, S., Bertoni, F., \& Trapasso, F. (2018). T-cell leukemia/lymphoma 1 (TCL1): An oncogene regulating multiple signaling pathways. Frontiers in Oncology, 8, 317.

Pauken, C. M., \& Capco, D. G. (1999). Regulation of cell adhesion during embryonic compaction of mammalian embryos: Roles for PKC and $\beta$-catenin. Molecular Reproduction and Development, 54, 135-144.

Pearce, L. R., Komander, D., \& Alessi, D. R. (2010). The nuts and bolts of AGC protein kinases. Nature Reviews Molecular Cell Biology, 11, 9-22.

Pekarsky, Y., Koval, A., Hallas, C., Bichi, R., Tresini, M., Malstrom, S., \& Croce, C. M. (2000). Proceedings of the National Academy of Sciences USA, 97, 3028-3033.

Ragone, G., Bresin, A., Piermarini, F., Lazzeri, C., Picchio, M. C., Remotti, D., \& Russo, G. (2009). The Tcl1 oncogene defines secondary hair germ cells differentiation at catagen-telogen transition and affects stem-cell marker CD34 expression. Oncogene, 28, 1329-1338.

Riley, J. K., Carayannopoulos, M. O., Wyman, A. H., Chi, M., Ratajczak, C. K., \& Moley, K. H. (2005). The PI3K/Akt pathway is present and functional in the preimplantation mouse embryo. Developmental Biology, 284, 377-386.

Sarbassov, D. D., Guertin, D. A., Ali, S. M., \& Sabatini, D. M. (2005). Phosphorylation and regulation of Akt/PKB by the rictor-mTOR complex. Science, 307, 1098-1101.

Tschopp, O., Yang, Z. Z., Brodbeck, D., Dummler, B. A., HemmingsMieszczak, M., Watanabe, T., \& Hemmings, B. A. (2005). Essential role of protein kinase $B$ gamma (PKB gamma/Akt3) in postnatal brain development but not in glucose homeostasis. Development, 132, 2943-2954.

Virgilio, L., Narducci, M. G., Isobe, M., Billips, L. G., Cooper, M. D., Croce, C. M., \& Russo, G. (1994). Identification of the TCL1 gene involved in Tcell malignancies. Proceedings of the National Academy of Sciences USA, 91, 12530-12534.

Wu, D., Yu, D., Wang, X., \& Yu, B. (2016). F-actin rearrangement is regulated by $\mathrm{mTORC2} / \mathrm{Akt} / \mathrm{Girdin}$ in mouse fertilized eggs. Cell Proliferation, 49(6), 740-750.

Yang, Z. Z., Tschopp, O., Di-Poï, N., Bruder, E., Baudry, A., Dümmler, B., \& Hemmings, B. A. (2005). Dosage-dependent effects of Akt1/protein kinase $B$ alpha (PKB alpha) and Akt3/PKB gamma on thymus, skin, and cardiovascular and nervous system development in mice. Molecular and Cellular Biology, 25(23), 10407-10418.

Zhang, X., Tang, N., Hadden, T. J., \& Rishi, A. K. (2011). Akt, FoxO and regulation of apoptosis. Biochimica et Biophysica Acta/General Subjects, 1813, 1978-1986.

How to cite this article: Fiorenza MT, Russo G, Narducci MG, Bresin A, Mangia F, Bevilacqua A. Protein kinase Akt2/PKB $\beta$ is involved in blastomere proliferation of preimplantation mouse embryos. J Cell Physiol. 2019;1-9.

https://doi.org/10.1002/jcp.29229 